\title{
Forecasting Fishery Performance for Northern Shrimp (Pandalus borealis) on the Labrador Shelf (NAFO Divisions 2HJ)
}

\author{
D. G. Parsons and E. B. Colbourne \\ Science, Oceans and Environment Branch, Department of Fisheries and Oceans \\ P. O. Box 5667, St. John's, Newfoundland, Canada A1C 5X1
}

\begin{abstract}
The physical environment of the ocean is believed to have a major influence on pandalid shrimp populations and there are numerous studies that incorporate environmental variables to predict and forecast landings from the fishery and/or resource abundance. Cause-and-effect mechanisms are not clearly understood in many instances but the predictive nature of the relationships provides a potentially powerful forecasting tool. Meaningful indicators of the prospects for shrimp stocks that support valuable commercial fisheries are necessary in a comprehensive stock assessment process.

In this paper, a time-series analysis is used to estimate a predictive model for standardized annual catch rates (an abundance index) in a shrimp fishing area off the mid Labrador coast (NAFO Div. 2HJ). Environmental data (annual winter ice cover) are incorporated in a transfer function to improve predictions of catch rates and facilitate their forecasting. Results support the hypothesis that cold conditions, which result in more extensive ice cover, are favourable for the northern shrimp (Pandalus borealis) at early life-history stages. Predictions of annual catch rates fit the observed values well in most cases and a catch-rate forecast for several years is provided. Possible functional mechanisms are discussed.
\end{abstract}

Key words: abundance, environment, Labrador Shelf, Pandalus, shrimp

\section{Introduction}

The importance of environmental (oceanographic) influences in affecting the dynamics of pandalid shrimp populations has been recognized for many years (e.g. Rasmussen, 1953) and is widely accepted. Nevertheless, the statistical relationships have been demonstrated rarely and the functional relationships, in most cases, have not been clearly explained. The decline of the shrimp (Pandalus borealis) resource in the Gulf on Maine during the 1970s was well documented but opinions were divided on the relative importance of natural and anthropogenic factors (see Apollonio et al., 1986; Clark, et al., 2000). The collapse of the Alaskan fishery for $P$. borealis (renamed P. eous by Squires, 1992) during the late-1970s prompted an extensive review of the literature on the relationship between shrimp distribution and physical oceano-graphic parameters (Ippolito et al., 1980). The proceedings of the international pandalid shrimp symposium held in Kodiak, Alaska in 1979 (Frady, 1981) included research presentations and panel discussions on the importance of environmental factors to pandalid shrimp. Subsequently, Nunes (1984) conducted major studies that demonstrated effects of temperature on shrimp reproduction and larval survival. This Symposium on Pandalid Shrimp Fisheries - Science and Management at the Millennium - devoted an entire session to environmental and trophic considerations, concluding that these factors "... must play an increasingly important role in the assessment and management of pandalid populations in the future." (NAFO, 2000).

Predictions of shrimp landings/abundance based on correlations with environmental variables have taken a variety of forms. Driver (1978) included predictions of mean Zurich sunspot number with meteorological variables to forecast abundance of Crangon crangon in the Irish Sea for several years. Sheridan (1996) associated indices of fishing activity with measurements of surface and ground-water levels to make short-term predictions of Penaeus duorarum landings off southwest Florida. De Pasquier (1998), in conducting a stock assessment for white shrimp (Penaeus schmitti) in Lake Maracaibo, Venezuela, incorporated temperature as an environmental variable in a modified surplus production model and concluded 
that catches can be predicted allowing for more efficient fishery management.

There are numerous examples of forecasting abundance of pandalid shrimp. Dow (1966) suggested that seawater temperatures from Boothbay Harbour (Maine, U.S.A.) could be used to predict relative abundance of commercial-sized shrimp in the Gulf of Maine two years later. This was reworked to a longerterm forecast based on the negative relationship between catch and mean seawater temperature four years earlier (Dow, 1977). Warren (MS 1973) observed that, over a fifty-year period, annual mean water temperature in the Wash (United Kingdom) was inversely related to pink shrimp ( $P$. montagui) landings in the following year. Lysy and Dvinina (MS 1991) showed, that in areas of the Barents Sea, water temperatures in spring could be used to forecast the size of the $P$. borealis stock up to 3 years. Hannah (1993, 1999) demonstrated a strong, negative correlation between recruitment of ocean shrimp (P. jordani) to the fishery off Oregon, U.S.A., and sea level height in the previous year but conceded that the precise mechanism for the relationship remains speculative. A recent, unpublished study in the Gulf of St. Lawrence (Canada) showed that models of nitrate levels in surface water layers might be useful to predict commercial catch rates of $P$. borealis up to three years (J. Plourde, Department of Fisheries and Oceans, Mont-Joli, Quebec, pers. comm.).

Fogarty (1989), in describing methods to forecast yield and abundance of invertebrates, distinguished between structural and heuristic models. The structural models deal with cause and effect in describing relationships within natural systems whereas the latter recognize recurrent patterns in time series without implying causality. Nunes (1984) stated that the correlation (heuristic) studies have only limited value since they do not explain the direct effects of environmental factors. Fogarty (1989) argued that it is often impossible to manipulate natural systems within strictly controlled experiments and, therefore, the only alternative is to investigate factors for which there are reasons to suspect causal relationship. At risk of taking both authors out of context, we enter the "argument" from the viewpoint that, in addition to establishing current resource status, the stock assessment process for northern shrimp, $P$. borealis, must utilize forecasting tools to comment on prospects for recruitment and spawning stock biomass. Heuristic models might not serve well in our understanding of natural processes but can provide accurate predictions and forecasts and, as stated by Fogarty (1989), serve as the foundation for future research. This was supported in part by Hannah (1993) who noted that, despite limitations, correlative studies could be important for shrimp to develop hypotheses about environmentally driven recruitment.

This paper was inspired by the notion of Fogarty (1989) that it may be possible to obtain accurate forecasts with heuristic models using an approach (Box and Jenkins, 1976) that provides a formal structure within an adaptable framework. We use timeseries analysis that incorporates environmental data to construct predictive models for standardized catch rates (an abundance index) in a northern shrimp (P. borealis) fishing area off the mid Labrador coast (Div. 2HJ). The underlying hypothesis is that "cold conditions" are favourable for shrimp at early lifehistory stages.

\section{Materials and Methods}

\section{Study area}

Two depressions (marginal troughs) in the mid Labrador Shelf, known as the Hopedale and Cartwright Channels (Fig. 1), have supported commercial, bottom-trawl fisheries for northern shrimp since the mid-1970s. The deepest, landward portions of these channels $(>500 \mathrm{~m})$ are connected to the seaward shelf edge by a saddle with depths greater than $200 \mathrm{~m}$. Commercial concentrations of shrimp occur primarily in depths between 200 and $500 \mathrm{~m}$ within the channels and saddles and along the shelf edge. Initially, shrimp within each channel were treated as separate stocks but, beginning in 1994, were combined for assessment/management purposes. Fishing grounds throughout the area, especially within the channels, are largely ice covered in winter, spring and even early summer in cold years. During warm years, the ice is restricted to the Labrador Shelf allowing year-round fishing along the shelf edge.

\section{Fishery data}

Catch (kg) and effort (hours fished) from commercial vessel log records were compiled for all years from 1977 to 1998 within the shrimp fishing area. Catch-per-unit-effort (CPUE), expressed as kg per hour, was calculated by year. The raw CPUE data were standardized by multiple regression in an attempt to account for variation due to factors such as year, month, area and vessel (Parsons et al., MS 1999). The annual series (Fig. 2), (standardized to: July; the 


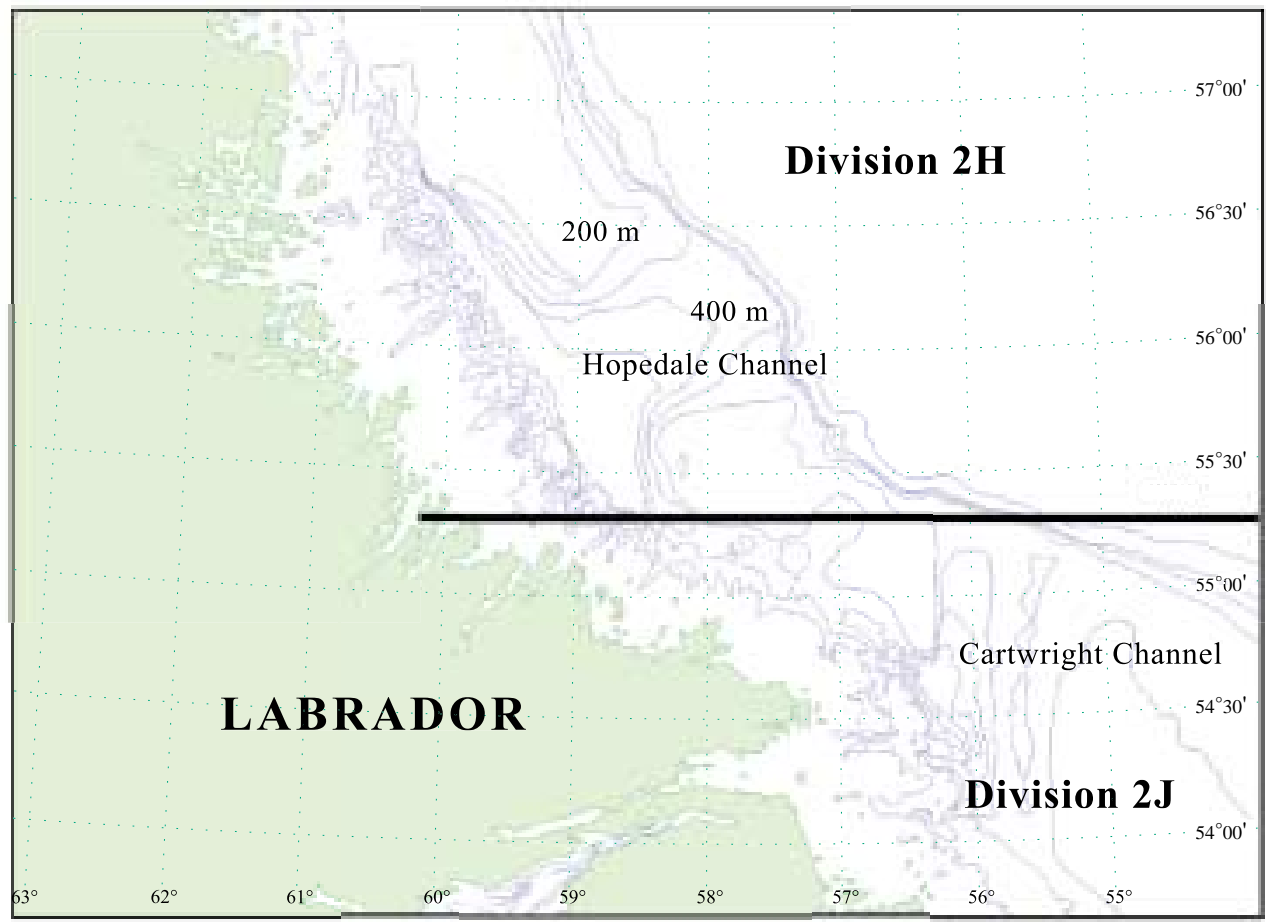

Fig. 1. Location of Hopedale and Cartwright Channels off Labrador.

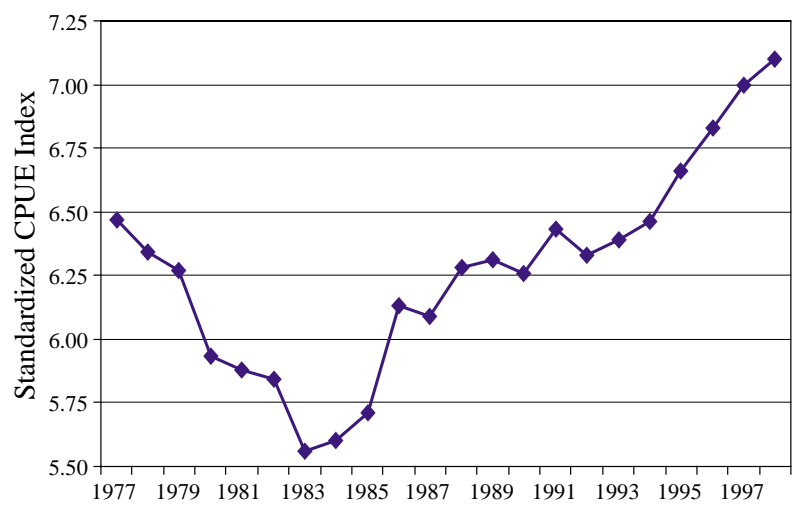

Fig. 2. Standardized catch-per-unit-effort index for Hopedale and Cartwright Channels, 1977-98 (from Parsons et al., MS 1999).

northern portion of Hopedale Channel; and the fishing power of a vessel of long-standing in the fishery) has been used as a measure of fishery performance and as an indicator of change in the fishable stock over time. Natural $\log (\ln )$ CPUE values for each year, output from the regression analysis, were used in the current modeling exercise.

\section{Environmental data}

Several environmental variables, expressed as annual values, were examined during preliminary investigations of possible associations with trend in shrimp CPUE. These included bottom temperature at a hydrographic monitoring site (Station 27) off St. John's, Newfoundland, cross-sectional area of the cold intermediate layer (CIL) off northeastern Newfoundland, location of the Gulf Stream front and several measures of ice cover off the northeast Newfoundland and southern Labrador coast. The series (1970-98) of annual, winter (January-March) ice cover $\left(\mathrm{km}^{2}\right)$ for the area between $45^{\circ}$ and $55^{\circ} \mathrm{N}$, as presented by Drinkwater et al. (MS 1999) (Fig. 3), was chosen for two reasons. Initially, it provided marginally improved correlations with CPUE compared to other data and, particularly, was more meaningful when considering possible functional relationships.

\section{Modeling procedures}

An autoregressive, integrated, moving-average (ARIMA) procedure was used to derive predictive models for shrimp CPUE. These also are known as Box-Jenkins (1976) models that, procedurally, are described in three steps:

1. Identify: autoregressive and/or moving-average process in the response series (i.e. CPUE),

2. Estimate: specify the model to fit to the variable and estimate its parameters, and

3. Forecast: generate future values of the response series and confidence intervals for the forecasts. 


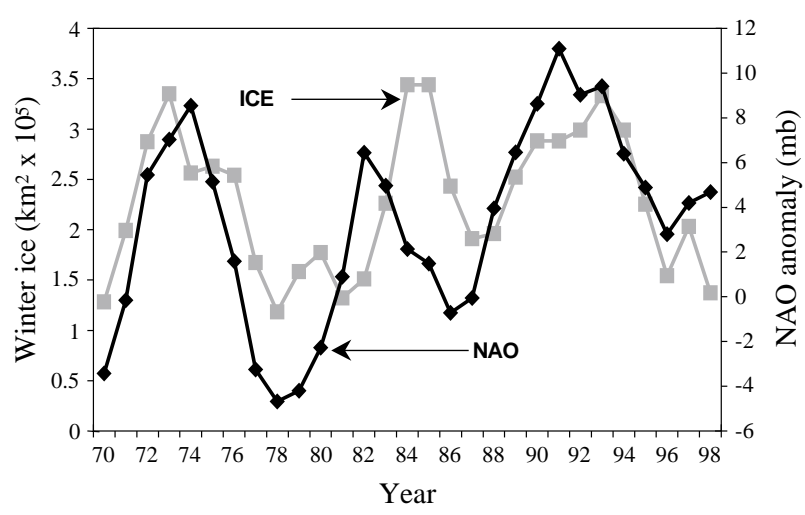

Fig. 3. Area of winter (Jan-Mar) ice cover $\left(\mathrm{km}^{2}\right)$ off Newfoundland-Labrador (from Drinkwater et al., MS 1999) and NAO anomalies (pressure difference in millibars, see Discussion), 197098.

Statistical analysis system software (SAS, 1984, 1993) was used for modeling. The models investigated in the current analysis included an input series (i.e. winter ice cover) in a transfer function. Transfer functions, in addition to modeling the response series (i.e. CPUE) using its own past values, incorporate current and past values of an input series. When delays are evident from valid crosscorrelations, inclusion of the input series can improve the forecasting power of the model.

The key to the identification step was matching theoretical autocorrelation functions of different autoregressive/moving-average processes with the sample functions obtained from the analysis. Diagnostic tools for the estimation step included significance tests for parameters, goodness-of-fit to compare the model to others and tests for "white noise" (uncorrelated) residuals. The white noise tests indicate whether the residual series contain additional information requiring more complex modeling.

\section{Results}

The identification step for the CPUE data produced autocorrelations that decayed rapidly indicating stationarity (no trend) in the series (Fig. 4a). Although the data (Fig. 2) showed short-term trends (i.e. a decline from 1977 to 1983, and an increase thereafter, particularly during the 1990s), there was no overall long-term trend. Therefore, differencing (modeling the change in CPUE from year to year rather than the CPUE series itself) was not necessary. The autocorrelation functions (full, inverse and partial) further indicated a first-order, auto- regressive process, characterized by significant autocorrelations at a lag of one year. The inclusion of an autoregressive parameter (1-year lag) in the estimation step achieved "white noise" residuals (Table 1) and no additional parameterization was required. Several estimation trials showed moving average parameters were either insignificant or created instability in the model. The autoregressive model predicts the CPUE as an average, plus some fraction of the previous CPUE, plus a random error.

Similarly, the winter ice input series revealed a stationary, first-order, autoregressive process (Fig. 4b). Again, the inclusion of a single, autoregressive parameter (1-year lag) reduced residuals to "white noise" (Table 2) and more complex modeling was not considered necessary. These results are consistent with analyses of other environmental data (e.g. CIL) that also have shown significant autocorrelation at a lag of one year (Shelton et al., 1999).

In constructing the transfer function, which involved crosscorrelation of the two autocorrelated series, both the input and response variables were filtered with a "prewhitening" model. Fogarty (1989) explained that a time series model (in this case an autoregressive model of order 1) is first fit to the input series so that residuals are independent (reduced to white noise). Then, using the same model, the input series is filtered followed by the response series. Residuals are crosscorrelated rather than the original series. Crosscorrelations for the prewhitened series (Fig. 5) showed highest correlations at shifts of 0 and 6 years. With no shift, the relationship was negative (0.42 ) whereas, with a shift of 6 years, the relation-ship was positive (0.39).

The simplest transfer function model with forecasting potential and for which residuals were reduced to white noise included a first-order autoregressive parameter for the CPUE series and the winter ice series with a shift or delay of 6 years. The input series, however, contributed far less to the model than either the mean term, which was most important, or the autoregressive parameter. Other model specifications included an estimated intercept of 6.2573 , an autoregressive factor of $1-0.9682 \mathrm{~B}^{* *}(1)$ and an overall regression factor of 0.1121 (Table 3 ).

Predictions of annual ln CPUE were close to the observed values in most cases (Fig. 6). The six-year forecast from 1999 to 2004 showed an increase in CPUE for 1999 followed either by stability or, at worst, a decline by as much as $50 \%$. 


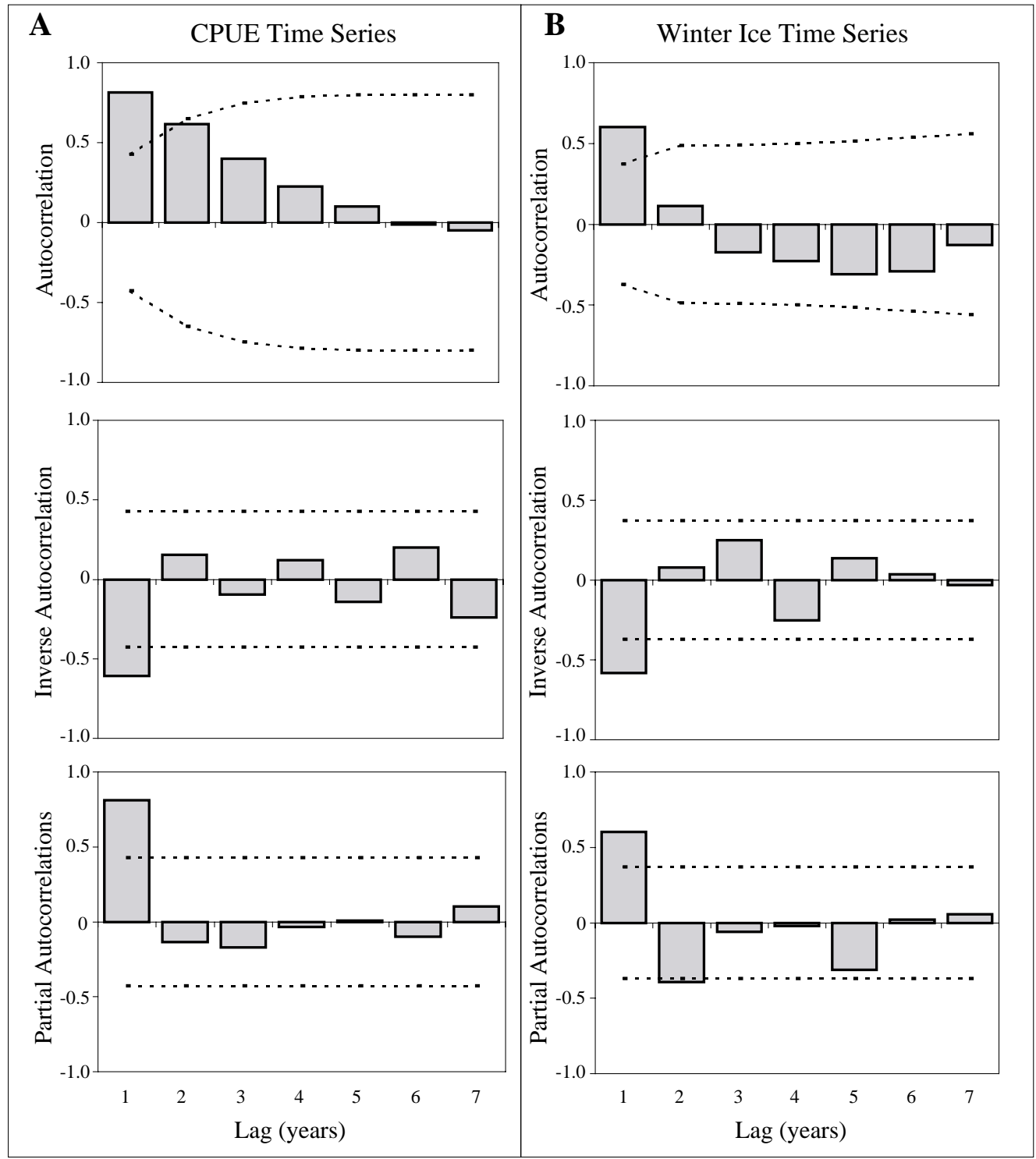

Fig. 4. (A) Autocorrelations \pm 2 standard errors (dotted line) for variable $\ln$ CPUE from ARIMA modeling; mean of series $=6.266818$, standard deviation $=0.403669$, number of observations $=22$. (B) Autocorrelations \pm 2 standard errors (dotted line) for winter ice input variable from ARIMA modeling; mean of working series $=2.292069$, standard deviation $=0.694036$, number of observations $=29$.

\section{Discussion}

The North Atlantic Oscillation (NAO) (Rogers, 1984 ) is generally regarded as one of the most robust indicators of climate variation in the north Atlantic. This index correlates with variations in several environmental variables in the northwest Atlantic including wind, salinity, temperature and ice. The correlation between the five-year, low-passed filtered winter NAO anomalies and the northeast Newfoundland Shelf ice cover anomalies was shown by Colbourne et al. (1997) to be $0.72(P=0.05)$. Similarity in the temporal fluctuations of the winter ice series and the NAO anomalies (Fig. 3) suggests that the former is a reflection of broad-scale climatic conditions. Larvae of Pandalus borealis hatch in spring, under the ice cover, from eggs carried by the females. Larvae are known to remain for several weeks during the spring and summer in the near-surface water layers $(<50 \mathrm{~m})$ within the study area (Parsons et al., 1986). Therefore, it is reasonable to assume that variations in ice extent and subsequent melting may influence larval survival during this period. 
TABLE 1. Estimation of process parameters for shrimp CPUE from ARIMA modeling. $\mathrm{DF}=$ degrees of freedom.

\begin{tabular}{llllr}
\hline \hline Parameter & Estimate & Std Error & T Ratio & Lag \\
\hline Mean & 6.48305 & 0.17282 & 37.51 & 0 \\
Autoregressive & 0.97339 & 0.08470 & 11.49 & 1 \\
\hline
\end{tabular}

Autocorrelation Check of Residuals

\begin{tabular}{|c|c|c|c|c|c|c|c|c|c|}
\hline Lags & $\begin{array}{c}\text { Chi } \\
\text { Square }\end{array}$ & DF & Prob & & & Autocor & ections & & \\
\hline $1-6$ & 7.99 & 5 & 0.157 & 0.261 & 0.358 & 0.136 & -0.002 & 0.026 & -0.267 \\
\hline $7-12$ & 11.65 & 11 & 0.391 & 0.068 & -0.181 & 0.193 & 0.120 & 0.015 & 0.044 \\
\hline
\end{tabular}

TABLE 2. Estimation of process parameters for winter ice cover from ARIMA modeling. $\mathrm{DF}=$ degrees of freedom.

\begin{tabular}{lcccc}
\hline \hline Parameter & Estimate & Std Error & T Ratio & Lag \\
\hline Mean & 2.04578 & 0.30811 & 6.64 & 0 \\
Autoregressive & 0.69304 & 0.15070 & 5.60 & 1 \\
\hline
\end{tabular}

Autocorrelation Check of Residuals

\begin{tabular}{|c|c|c|c|c|c|c|c|c|c|}
\hline \multirow{2}{*}{$\frac{\text { Lags }}{1-6}$} & \multirow{2}{*}{$\begin{array}{c}\begin{array}{c}\text { Chi } \\
\text { Square }\end{array} \\
8.69\end{array}$} & \multirow{2}{*}{$\frac{\text { DF }}{5}$} & \multirow{2}{*}{$\begin{array}{c}\text { Prob } \\
0.122\end{array}$} & \multicolumn{6}{|c|}{ Autocorrections } \\
\hline & & & & 0.289 & -0.201 & -0.212 & 0.042 & -0.139 & -0.244 \\
\hline $7-12$ & 10.52 & 11 & 0.485 & -0.068 & 0.117 & 0.135 & 0.045 & 0.033 & 0.037 \\
\hline
\end{tabular}

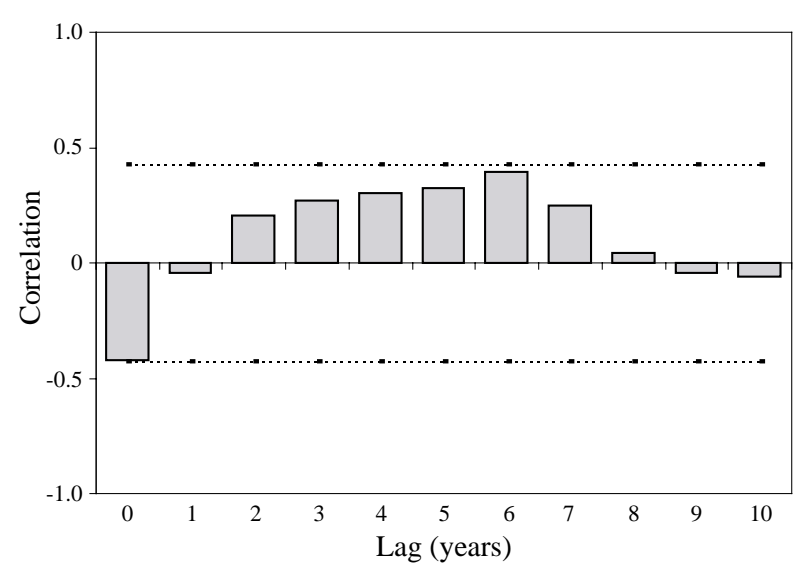

Fig. 5. Crosscorrelations ( \pm 2 standard errors - dotted line) for $\ln$ CPUE and winter ice from ARIMA modeling. Both variables were prewhitened by the following autoregressive filter: $1-0.69304 \mathrm{~B}^{* *}(1)$. Variance of transformed series $=0.041778$ and 0.276015 ; number of observations $=22$.
The above time-series analysis demonstrates a process by which forecasting tools for northern shrimp can be developed. Generally, for these types of models, there should be at least 30 observations. With fewer (as in this example where there are only 22 values within the response series), parameter estimates may be imprecise and standard errors and $t$-ratios unreliable (SAS, 1993). This data limitation brings into question our ability to identify with certainty the autoregressive (and/or moving average) processes, valid crosscorrelations between response and input variables and, ultimately, a representative transfer function. Indeed, the statistical significance of a relationship between shrimp CPUE and winter ice with a delay of six years is marginal within the current analysis. Nevertheless, other model formulations, using both unstandardized and standardized CPUE with different oceanographic input series, showed environmental signals in the crosscorrelations at 
TABLE 3. Estimation of transfer function parameters from ARIMA modeling. LNCPUE $=$ response series, WICE $=$ winter ice input series, $\mathrm{DF}=$ degrees of freedom.

\begin{tabular}{lccrrrc}
\hline \hline Parameter & Estimate & Std Error & T Ratio & Lag & Variable & Shift \\
\hline Mean & 6.25734 & 0.21298 & 29.380 & 0 & LNCPUE & 0 \\
Autoregressive & 0.96820 & 0.08234 & 11.76 & 1 & LNCPUE & 0 \\
Input series & 0.11208 & 0.06538 & 1.71 & 0 & WICE & 6 \\
\hline
\end{tabular}

Autocorrelation Check of Residuals

\begin{tabular}{|c|c|c|c|c|c|c|c|c|c|}
\hline Lags & $\begin{array}{l}\text { Chi } \\
\text { Square }\end{array}$ & DF & Prob & & & Autoc & rections & & \\
\hline $1-6$ & 8.56 & 5 & 0.128 & 0.298 & 0.409 & 0.067 & -0.061 & 0.070 & -0.215 \\
\hline $7-12$ & 13.23 & 11 & 0.279 & 0.037 & -0.243 & 0.153 & 0.118 & 0.110 & 0.068 \\
\hline
\end{tabular}

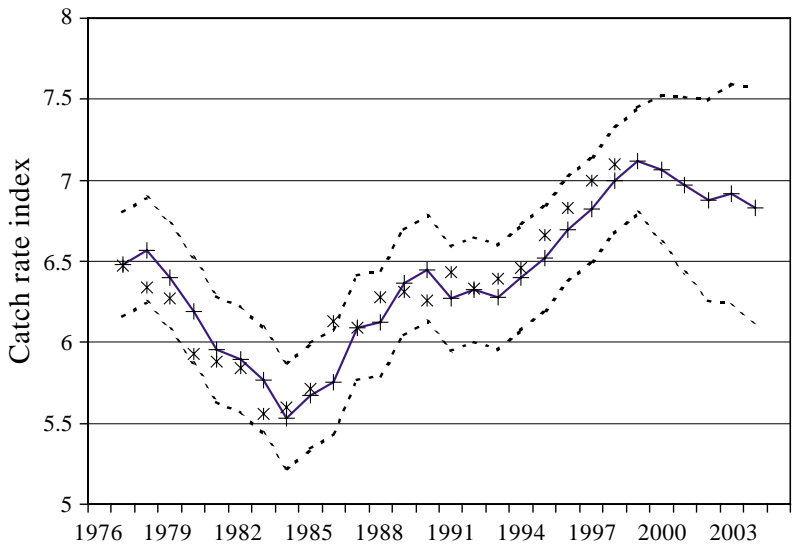

Fig. 6. Transfer function model for $\ln$ CPUE and winter ice input series with six-year forecast. Observed $={ }^{\prime} *$ ', predicted $={ }^{\prime}+$ ', and dotted lines $=95 \%$ confidence intervals.

various shifts or delays. For example, bottom temperature at Station 27 showed highest (negative) correlations at delays of 5 and 6 years. Maximum and spring ice cover were positively correlated, also at delays of 5 and 6 years, and area of the CIL at 7 years.

Regarding the CPUE index, the unstandardized series produced first order, autoregressive diagnostics that were similar to those of the standardized series, allaying concern about making conclusions that might be influenced by the regression analysis of the latter (S. Smith, Department of Fisheries and Oceans, Dartmouth, Nova Scotia, pers. comm.). The standardized series was used in order to achieve stability during the ARIMA estimation step.

The example presented showed that the mean of the CPUE series and its autoregressive parameter were important and that a first-order autoregressive model could fit the observed data adequately. A shrimp catch includes several year-classes (ages 4 to $7+$ ) and it is not surprising, therefore, that a significant autoregressive process was detected. (More surprising, perhaps, was the lack of significant, higher order parameters, given that a strong year class can contribute substantially to the catches for more than two years.) However, the forecast capability of such a model is limited to only one time period. Although the winter ice input series did not contribute greatly to the model fit (Table 3), it did facilitate a forecast given the delay of six years as indicated in the crosscorrelations.

The highest crosscorrelations between $\ln$ CPUE and winter ice at delays of 0 and 6 years can be discussed in relation to the effects of ice cover on fishing activity and stock productivity. The relationship with no delay was negative and it is reasonable to assume that heavy ice in a given year might adversely affect fishing activity and CPUE. Optimal fishing grounds, in whole or part, would be inaccessible and effort diverted to fishable but less productive areas resulting in lower CPUE.

Extensive ice cover in cold years possibly contributes positively to survival of larvae and juveniles in the same year and the effect can be detected in the CPUE several years later (the mean age of shrimp in the catch is about 6 years). Mechanisms, however, are only speculative at this stage. Perhaps extensive ice cover serves simply to retain larvae and early juvenile stages within preferred areas (i.e. within the first $50 \mathrm{~m}$ ) prior to settlement, thereby enhancing recruitment to the fishable stock. In a slack ice year, retention might be reduced and 
dispersal of larvae and juveniles to hostile environments (i.e. lower survival) could be extensive. The ocean generally responds to climate variations through changes in the shelf stratification that, in this region, are due mainly to salinity changes, resulting from variations in ice formation and subsequent melting. During the melting period of a heavy ice year, the salinity cycle generally shows upper-layer salinities that are fresher than normal during spring and summer. This tends to increase the stratification and, hence, the stability of the water column, which is usually required to initiate and maintain maximum primary production within the euphotic zone. An adequate balance between nutrient supply and primary production would create favourable conditions for the survival of shrimp larvae in the upper water column. A recent study by Ramseier et al. (2000) showed that the extent of localized sedimentation of particulate organic carbon (POC) can be derived from information about ice cover. Given that POC is known to be important to the distribution of shrimp (Butler, 1971) and likely plays an important role as a food supply, it is possible that the explanation of the functional relationship is related more to nutrient supply than temperature-related phenomena. This would help explain the apparent inconsistencies between in situ observations, which suggest "cold conditions" are favourable for shrimp, and laboratory studies, which indicate that larval growth and survival are enhanced at higher temperatures (e.g. Wienberg, 1982; Nunes, 1984).

Failure of models that correlate environmental indices with some measure of recruitment is notorious. Pitfalls related to the difficulties in obtaining reliable estimates of recruitment for true production systems (as described by Frank, 1997) are minimal in the current modeling exercise. The crosscorrelations of CPUE and the input series of winter ice cover identified a delay of 6 years, which was used only inferentially with respect to recruitment as might be reflected in future CPUE, an index that includes several year classes. Myers (1998) noted that correlations with temperature that "held up" under re-analysis tended to be associated with populations close to the northern (i.e. cold: expect a positive relationship) or southern (i.e. warm: expect a negative relationship) limits of the species range and used northern shrimp in the Gulf of Maine as an example of the latter. Although shrimp off the mid Labrador coast are not at the limits of the geographic range in a north-south context, they are restricted within the area to a preferred temperature/substrate range.
Positive effects of "cold conditions" were evident in both the Gulf of Maine and Labrador Shelf habitats.

Forecasting fishery performance and stock abundance for northern shrimp is a desirable adjunct to the stock assessment process. Assessment methodology for shrimp, currently used in eastern Canada and by NAFO, interprets and evaluates multiple indicators of stock performance to produce an overall, qualitative evaluation of resource status (Savard and Parsons, MS 1999; Koeller et al., 2000). However, most indicators reflect current status while relatively few address prospects for either recruitment (males) or spawning biomass (females). Despite a lack of information on future trends in shrimp stocks, longterm expectations by "stakeholders" are immense. Unfortunately, forecasts are never perfect and it is important that they be used cautiously and are not overemphasized during fisheries management planning. Myers (1998) commented that the rare use of environment-recruitment correlations to predict recruitment in assessments is evidence against their general usefulness. This is likely true for conventional, analytical assessments but must be reconsidered in the context of a process that considers multiple stock performance indices, possibly involving non-linear environmental interactions.

Shrimp populations react to environmental perturbations. The model presented here addresses a possible response to the physical/biological environment that should be periodically reviewed as new data become available to test its durability and investigate alternatives. Incorporation of an input series for predator abundance, another important factor in shrimp population dynamics, also should be given high priority.

\section{Acknowledgements}

We appreciate the efforts of the anonymous reviewers for contributing to and improving the manuscript through their many helpful comments and suggestions.

\section{References}

APOLLONIO, S., D.K. STEVENSON, and E.E. DUNTON, JR. 1986. Effects of temperature on the biology of the northern shrimp, Pandalus borealis, in the Gulf of Maine. NOAA Tech. Rep., NMFS 42: 22 p.

BOX, G.E.P., and J. JENKINS. 1976. Time series analysis: forecasting and control, revised edition, Holden-Day, San 
Francisco, CA: 575 p.

BUTLER, T. H. 1971. A review of the biology of the pink shrimp (Pandalus borealis). In: Proceedings Conference on the Canadian Shrimp Fishery, Saint. John, N.B., Oct. 27-29, 1970. Can. Fish. Rep., 17: 17-24.

CLARK, S.H., S. CADRIN, D. SCHICK, P. DIODATI, M. ARMSTRONG, and D. MCCARRON. 2000. The Gulf of Maine northern shrimp (Pandalus borealis) fishery: a review of the record. J. Northw. Atl. Fish. Sci., 27: 193-226 (this volume).

COLBOURNE, E., B. DeYOUNG, S. NARAYANAN, and J. HELBIG. 1997. Comparison of hydrography and circulation on the Newfoundland Shelf during $1990-$ 1993 with the long-term mean. Can. J. Fish. Aquat. Sci., 54(Suppl. 1): $68-80$.

DE PASQUIER, G.J.A. 1998. The influence of environment on stock assessment: case of white shrimp, Penaeus schmitti, in Lake Maracaibo, Venezuela. Ciencia (Maracaibo), 6(3): 173-181.

DOW, R.L. 1966. A method of forecasting the relative abundance of northern shrimp (Pandalus borealis Kr.) in Maine waters. Commer. Rev., 28(3): 14-16.

1977. Effects of climate cycles on the relative abundance and availability of commercial marine and estuarine species. ICES J. Cons., 37: 274-280.

DRINKWATER, K.F., E. COLBOURNE, and D. GILBERT. MS1999. Overview of environmental conditions in the northwest Atlantic in 1998. NAFO SCR Doc., No. 36, Serial No. N4094, 72 p.

DRIVER, P.A. 1978. The prediction of shrimp landings from sunspot activity. Mar. Biol., 47: 359-361.

FOGARTY, M.J. 1989. Forecasting yield and abundance of exploited invertebrates. Chapter 31. In: Marine Invertebrate Fisheries, Their Assessment and Management. Caddy, J.F. (ed.) John Wiley and Sons: $752 \mathrm{p}$

FRADY, T. (ED.) 1981. Proceedings of the International Pandalid Shrimp symposium, Kodiak, Alaska. Sea Grant Report, 81(3) 519 p.

FRANK, K. T. 1997. The utility of early life history studies and the challenges of recruitment prediction. Chapter 18. In: Early Life History and Recruitment in Fish Populations. Chambers, R.C., and E.A. Trippel (eds.) Chapman \& Hall, London. ISBN 0412641909.

HANNAH, R.W. 1993. Influence of environmental variation and spawning stock levels on recruitment of ocean shrimp (Pandalus jordani). Can. J. Fish. Aquat. Sci., 50: $612-622$.

1999. A new method for indexing spawning stock and recruitment in ocean shrimp, Pandalus jordani, and preliminary evidence for a stock-recruitment relationship. Fish. Bull., 97: 482-494.

IPPOLITO, A., H.J. NIEBAUER, T. NISHIYAMA, and T. WEINGARTNER. 1980. A literature search: relationship between the distribution of pink shrimp, Pandalus borealis, and oceanographic parameters. Alaska Sea Grant Report, 79-11, 31p.

KOELLER, P., L. SAVARD, D. G. PARSONS, and C. FU. 2000. A precautionary approach to assessment and management of shrimp stocks in the Northwest Atlantic. J. Northw. Atl. Fish. Sci., 27: 235-246.
LYSY, A. YU., and E.A. DVININA. MS 1991. On relation of the deep sea shrimp stock size with oceanographic conditions in the Barents Sea. ICES C.M. Doc., No. $\mathrm{K}: 52: 18 \mathrm{p}$.

MYERS, R. A. 1998. When do environment-recruitment correlations work? Reviews in Fish Biology and Fisheries, 8: 285-305.

NAFO. 2000. NAFO Scientific Council Reports, 1999. Part C. NAFO Sci. Coun. Rep., 1999, p. 203-236.

NUNES, P. 1984. Reproductive and larval biology of northern shrimp, Pandalus borealis Kroyer, in relation to temperature. Ph. D. Thesis, University of Alaska, $195 \mathrm{p}$.

PARSONS, D. G., G. R. LILLY, and G. J. CHAPUT. 1986. Age and growth of northern shrimp Pandalus borealis off northeastern Newfoundland and southern Labrador. Trans. Amer. Fish. Soc., 115: 872-881.

PARSONS, D. G., P. J. VEITCH, and G. T. EVANS. MS 1999. Resource status of northern shrimp (Pandalus borealis) off Baffin Island, Labrador and northeastern Newfoundland - second interim review. Can. Stock Ass. Sec. Res. Doc., No. 112, 53 p.

RAMSEIER, R.O., C. GARRITY, and D. G. PARSONS and P. KOELLER. 2000. Influence of Particle Organic Carbon Sedimentation within the Seasonal Sea-ice Regime on the Catch Distribution of Northern Shrimp (Pandalus borealis). J. Northw. Atl. Fish. Sci., 27: 35-44 (this volume).

RASMUSSEN, B. 1953. On the geographical variation in growth and sexual development of the deep sea prawn (Pandalus borealis Kr.). Rep. Norweg. Fish. and Mar. Invest., 10(3), $160 \mathrm{p}$.

ROGERS, J.C. 1984. The association between the north Atlantic oscillation and the southern oscillation in the northern hemisphere. Mon. Weather Rev., 112: 19992105.

SAS. 1984. SAS Applied Time Series Analysis and Forecasting. Cary, NC: SAS Institute Inc.: 512 p.

1993. SAS/ETS User's Guide, Version 6, Second Edition, Cary, NC: SAS Institute Inc.: 1022 p.

SAVARD, L., and D. G. PARSONS. MS 1999. A precautionary approach to assessment and management of pandalid shrimp with application to Pandalus borealis in NAFO Division 3M. NAFO SCR Doc., No. 15, Serial No. N4063, $11 \mathrm{p}$.

SAVARD, L., D. G. PARSONS, C. FU, and P. KOELLER. MS 1999. A Precautionary Approach to Assessment and Management of Shrimp Stocks in the Northwest Atlantic. NAFO SCR Doc., No. 98, Serial No. N4177, $14 \mathrm{p}$.

SHELTON, P. A., G. R. LILLY and E. COLBOURNE. 1999. Patterns in the annual weight increment for Div. $2 \mathrm{~J}+3 \mathrm{KL}$ cod and possible prediction for stock projection. $J$. Northw. Atl. Fish. Sci., 25: 151-159.

SHERIDAN, P. 1996. Forecasting the fishery for pink shrimp, Penaeus duorarum, on the Tortugas Grounds, Florida. Fish. Bull., 94: 743-755.

SQUIRES, H. J. 1992. Recognition of Pandalus eous Makarov, 1935, as a Pacific species not a variety of the Atlantic Pandalus borealis Kroyer, 1838 (Decapoda, Caridea). Crustaceana, 63(3): 257-262. 
WARREN, P. J. MS 1973. The fishery for the pink shrimp Pandalus montagui in the Wash. Laboratory Leaflet (New Series), No. 28, Fisheries Laboratory, Lowestoft, Suffolk, UK, 46 p.
WIENBERG, R. 1982. Studies on the influence of temperature, salinity, light and feeding rate on laboratory reared larvae of deep sea shrimp, Pandalus borealis Kroyer 1838. Meeresforschung, 29(3): 136-153. 